\title{
Biotechnology and Educational Awareness as Ecological Means to Handle Organic Residues
}

\author{
Topwe Milongwe MWENE-MBEJA* \\ Department of Chemistry, University of Lubumbashi, Congo (DRC)
}

*Corresponding author: Topwe Milongwe MWENE-MBEJA, Department of Chemistry, University of Lubumbashi, Congo (DRC)

\section{Introduction}

Generally speaking, organic residues are mainly composed by carbohydrates, proteins and lipids residues. These kinds of residues should be managed properly to prevent the deterioration of the environment. Indeed, they can alter the quality of surface and underground water. For instance, the degradation of organic constituents, such as glucose, requires oxygen (Scheme 1) and consequently the oxygen content decreases. Such low oxygen content conditions harm the development of fish and other aquatic organisms [1].

$$
\mathrm{C}_{6} \mathrm{H}_{12} \mathrm{O}_{6}+6 \mathrm{O}_{2} \rightarrow 6 \mathrm{CO}_{2}+6 \mathrm{H}_{2} \mathrm{O}
$$

(Scheme 1)

As we know, water is a notable natural resource because it provides many social, economic and services to human beings and the environment. From this perspective, water remains a vital resource to be preserved because the accumulation of organic residues in the environment alters the quality of the water. Indeed, during periods of rain, organic waste can reach rivers, aquifers, lakes and oceans. The result is a degradation of water quality. Such degradation occurs, when the pollutants reach directly or indirectly the streams without appropriate treatment to remove unwanted organic substances. These can affect plants and other living organisms in water. From this point of view, it is important to recall the notable role of aquatic plants. These are home to fish, amphibians as well as invertebrates and allow them to feed themselves. Aquatic organisms without the presence of aquatic plants would sometimes find it very difficult to survive and flourish [1].

In this perspective, the foliage of aquatic plants protects the water against the sun's rays, and this helps to maintain a stable and temperate temperature which allows flora and fauna to grow [1]. Similarly, rooted aquatic plants also allow the stabilization of sediment in water. They participate in the filtration of water, the absorption of contaminants as well as the excess chemical nutrients [1]. In other words, when the equilibrium is broken and the concentrations of the nitrate ions and phosphorus are too high in the aquatic environment, the excess of nitrate ions $\left(\mathrm{NO}^{3-}\right)$ and phosphorus (P) contributes to the proliferation of algae [1]. From this point of view, aquatic plants absorb nitrate ions and use phosphorus to grow and that limits the proliferation of algae. These cyanobacteria produce toxins, which are harmful to humans and for animals [1]. The proliferation of algae gives the water a less attractive green hue, a viscous appearance and a bad odor. When the algae die, they deposit at the bottom of the lake and degrade [1]. Indeed, the degradation of the organic constituents of algae consumes oxygen (Scheme 1).

\section{Biotechnology}

When organic residues are not processed efficiently, they are broken down by microorganisms and this favors the multiplication of insects, which can prove to be true vectors of disease. Odors from organic decomposition sites also affect quality of life. To solve the problem of organic residues, biotechnology is an ecological means to handle properly organic residues in sense that these kinds of residues are enzymatically transformed to produce methane as well as organic and mineral fertilizers under the action of microorganisms. Regarding organic residues, biotechnology helps to promote agriculture because nutrient rich secondary products are used as fertilizers. The valorization of organic residues by means of biotechnology contributes enormously to the improvement of hygiene, reduces bad odors and the use of nonnatural fertilizers and pesticides. Biotechnology also minimizes incineration, and dumping of organic residues in landfills, and this reduces emissions of greenhouse gases. Indeed, the incineration of organic residues essentially produces greenhouse gases such as carbon dioxide and nitrogen dioxide [2,3]. Energy from biogas is 
very important especially in regions lacking energy infrastructure because it reduces the use of fossil fuels, limits deforestation and improves people's livelihoods who prepare food with firewood $[2,3]$. Such ecological transformation is a good strategy to clean up the environment and improve agriculture, particularly in underdeveloped countries, such as Democratic Republic of Congo.

\section{Educational Awareness}

Educational awareness is essential regarding sustainable development and protection of the environment. For example, population can be sensitized in order not to incinerate or dispose of residual organic residues into the rivers, streets or mixing them with toxic residuals but rather to keep them into containers, which are intended for the collection of organic residues. Awareness through education is fundamental in terms of reducing environmental pollution due to human activities.

\section{Conclusion}

In terms of health, living in an environment free from waste, particularly organic residues, this contributes enormously to public health and the development of society. Domestic, agricultural and industrial environments produce organic waste, which need to be collected, stored and recycled in order to avoid environmental pollution.

\section{References}

1. Mwene-Mbeja TM (2017) Deforestation and chemical water quality. Eur J Sci Res 144: 129 .

2. Chen TC, Lin CF (2008) Greenhouse gases emissions from waste management practices using Life Cycle Inventory model. J Hazardous Materials 155(1-2): 23-31.

3. Pham CH, Triolo JM, Cu TTT, Pedersen L, Sommer SG (2013) Validation and recommendation of methods to measure biogas production potential of animal manure. Asian-Australas J Anim Sci 26(6): 864-873.
To Submit Your Article Click Here: Submit Article

DOI: $10.32474 /$ CTBM.2020.01.000120

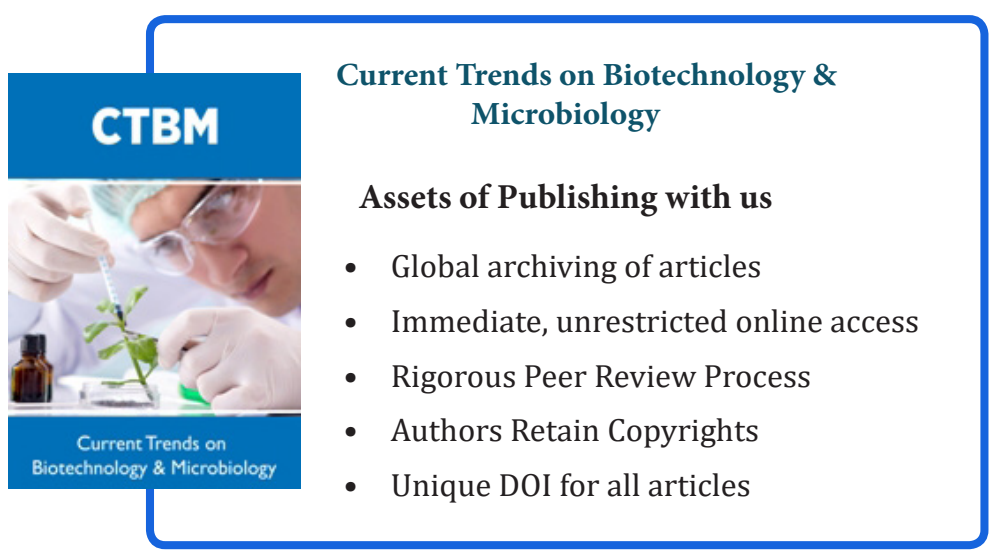

